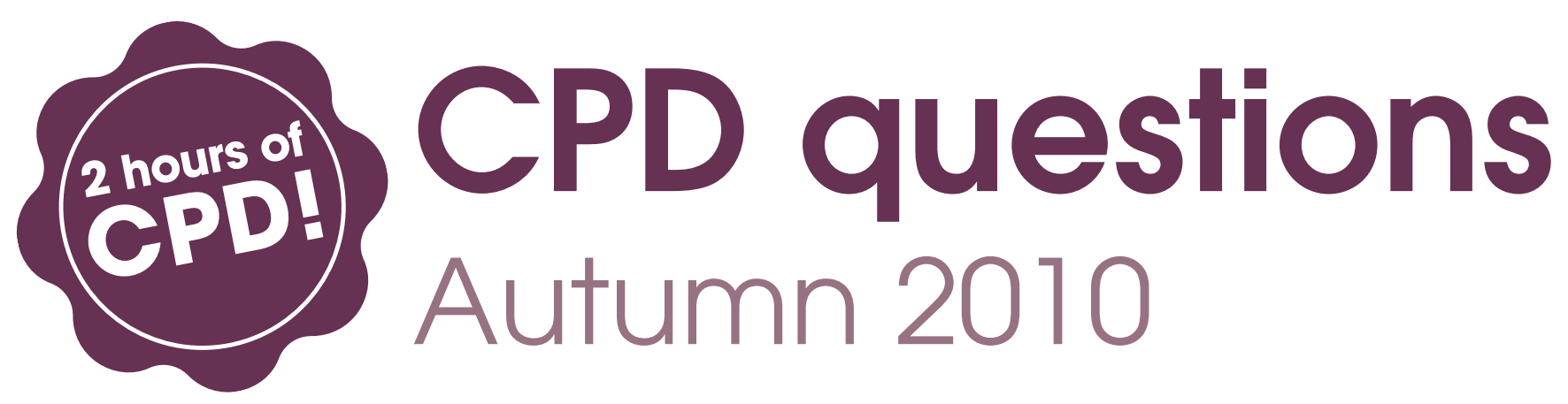

CPD ARTICLE 1 - PAGES 22-25

\section{Management of dental anxiety}

1. Which of the following does not describe a phobia?

A. embarrassment and shame are often present

B. it is a learnt response

C. the patient has little or no control over it

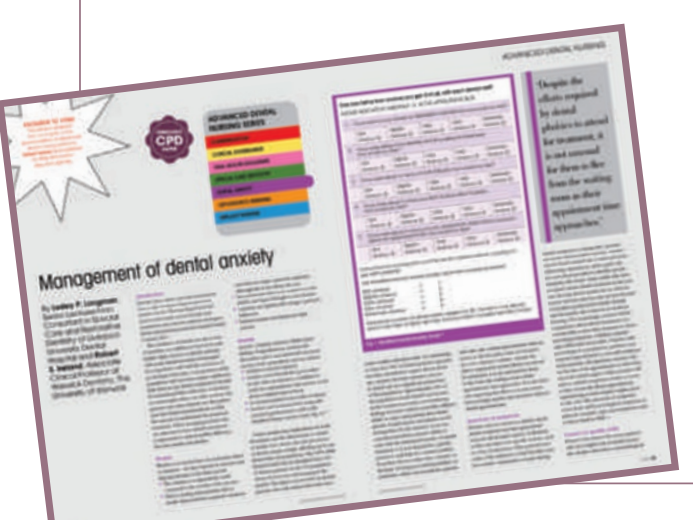

CPD ARTICLE 2 - PAGES 38-41

\section{Teaching of posterior composites to dental therapists}

1. What are the clinical advantages of composite when compared to amalgam?

A. composite sacrifices less healthy tooth tissue

B. composite restorations are minimally invasive

C. bonding composite to the underlying tooth reduces fracture risk

D. all of the above

2. In the results, $39 \%$ of the preclinical course was devoted to the teaching of posterior amalgam restorations. All ten centres taught the placement

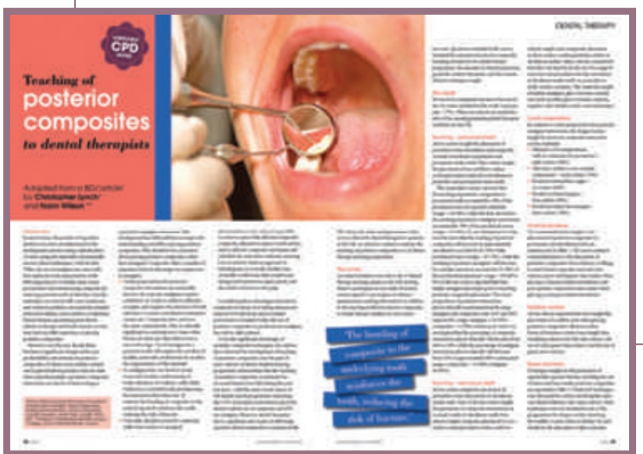

D. it is comparatively small compared to the severity of the reaction

2. A total score of 24 on the Modified Dental Anxiety Scale means:

A. extremely phobic

B. highly dentally anxious, possibly dental phobic

C. possibly anxious

D. not very anxious

3. Select the correct statistic from this article.

A. $46 \%$ of dentate patients reported that they attended for regular dental check-ups

B. $10 \%$ of dentate patients in the UK always feel anxious about dental visits

C. about $59 \%$ of the population avoids dental care due to dental phobia

D. $59 \%$ of dentate patients reported that they attended for regular dental check-ups

4. Rehearsal and explanation of the patient's psychosomatic reactions is a management strategy for a patient who:

\section{A. doesn't trust dentists}

B. has a needle phobia

C. has a fear of suffocating

$D$. is generally anxious

\section{CPD ANSWERS - SUMMER} Answers to the CPD questions in the
summer 2010 issue of Vital.

The role of dental therapist in the management of paediatric patients
with hypodontia

Q1. B

Q2. C

Q3. $A$

Q4. D

B. both statements are incorrect

C. the first statement is correct

D. the second statement is correct

3. Select the false statement.

A. rounded internal line angles for posterior composite restoration cavities were taught at six centres

B. the use of gauze was taught in two centres

C. one of the most common contraindications to the placement of posterior composites was poor oral hygiene

D. total-etch techniques were favoured for cavities involving the outer one-third of dentine only (ten centres)

4. Why is bevelling not in keeping with current best evidence?

A. bevelling can result in unnecessary loss of enamel

\section{Periodontal litigation and the dental}

Q1. B

Q2. A

Q3. D

Q4. C

B. bevelling

is linked to post-operative sensitivity

C. bevelling is associated with an increased risk of overhang production

D. bevelling does not adapt to the curved gingival margin of the proximal box

To submit your answers, please see the instructions on the following pages. The deadline for submission of this set of answers is 25 November 2010. 


\section{Vital verifiable CPD INSTRUCTIONS}

Online Vital verifiable CPD was launched in the summer 2008 issue of Vital. It offers DCPs the opportunity to complete eight hours of verifiable CPD per year for £30 (+VAT), by reading Vital articles.

Vital is published four times a year and 20,000 copies are distributed for free to a random selection of DCPS registered with the General Dental Council. For those who don't receive a free copy, Vital articles can be read for free on the Vital website at www.nature.com/vital. Just register for a log-in and password to gain access.

Reading Vital is free but Vital verifiable CPD costs $£ 30+$ VAT per year via our website: $\mathbf{w w w . n a t u r e . c o m / v i t a l c p d .}$

INSTRUCTIONS FOR ONLINE VERIFIABLE CPD

1. To register to obtain an account on the Vital website:

- Go to www.nature.com/vital

- In the top right hand corner of the screen it says 'register'.

Click here and enter your details to obtain an account.

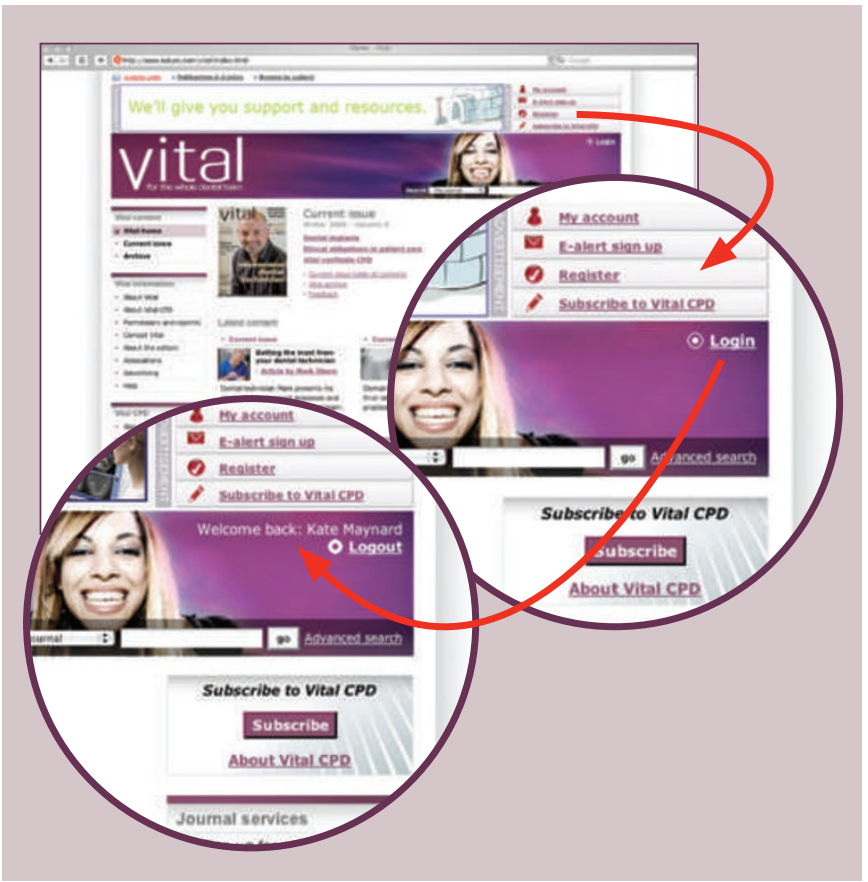

2. Log-in with your user name and password. It will say 'Welcome back: (your name)' at the top of the Vital homepage.
3. To subscribe to Vital CPD:

- Click on the button on the Vital website that says 'Subscribe to Vital CPD' or go directly to: www.nature.com/vitalcpd

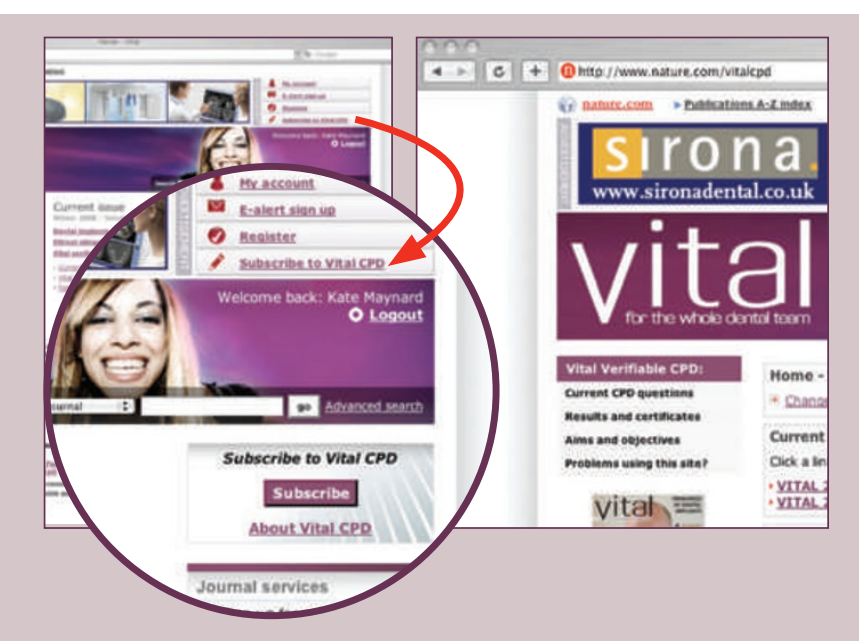

4. Click on 'subscribe now'

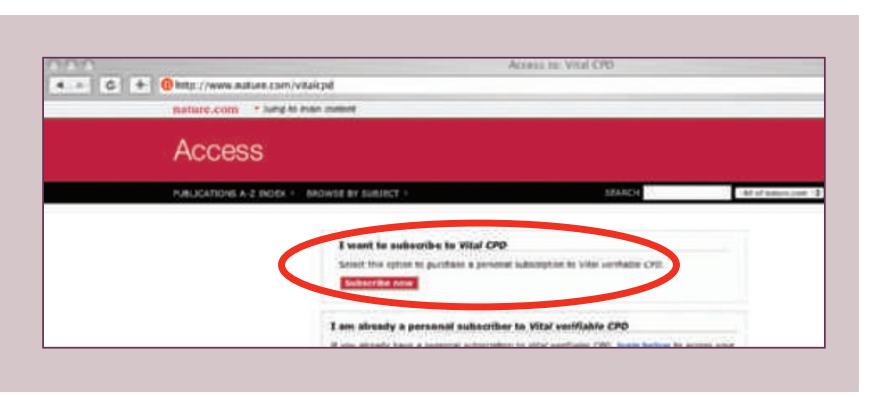


- Select 'I live in the United Kingdom' from the box at the top then follow the payment instructions

- After successfully purchasing your subscription online you will be emailed a temporary customer ID number which will be something like 'EC12345'.

5. When you have received your temporary customer ID number, return to the Vital homepage www.nature.com/vital (make sure you are logged in) and click on 'My Account' in the top right hand corner.

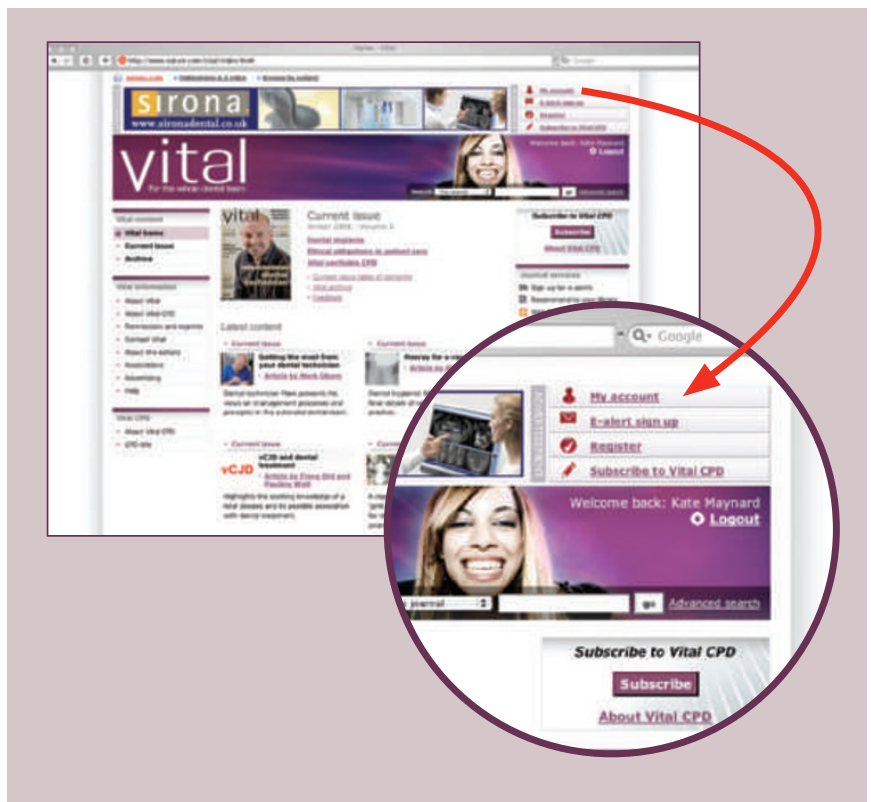

- Click on the tab that says 'subscriptions' at the top

- Enter your customer ID number beginning 'EC' and click on 'confirm' (you only need to do this once) to associate your CPD subscription with your Vital account.

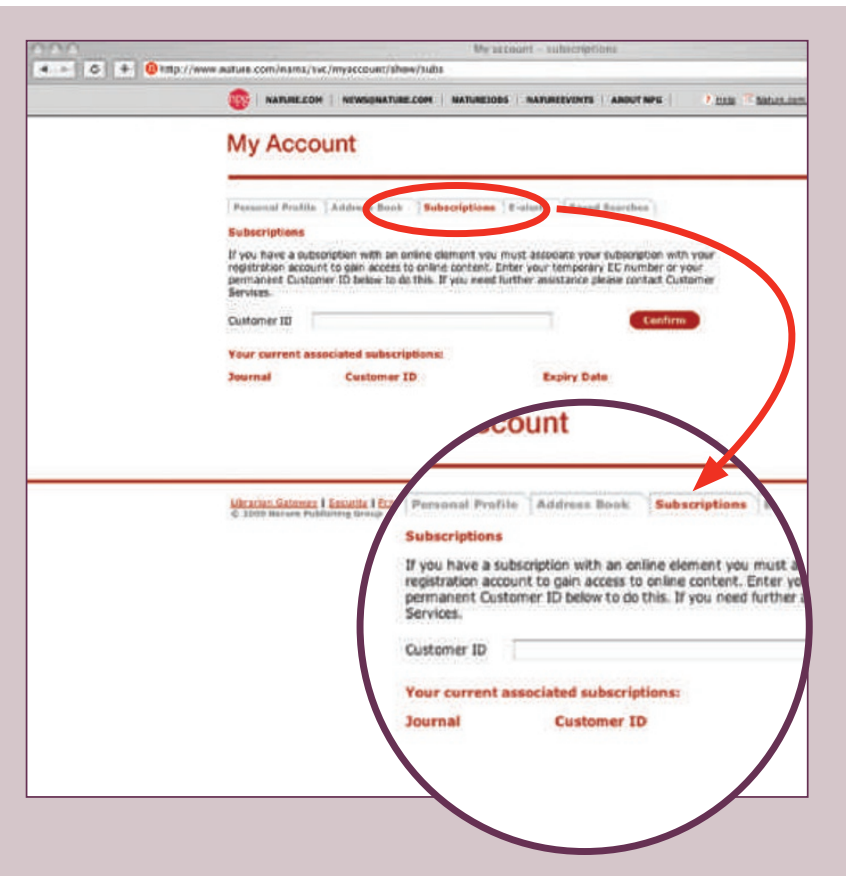

6. You are now ready to access Vital CPD. Click on 'CPD Site' on the homepage at www.nature.com/vital or go directly to www.nature.com/vitalcpd.

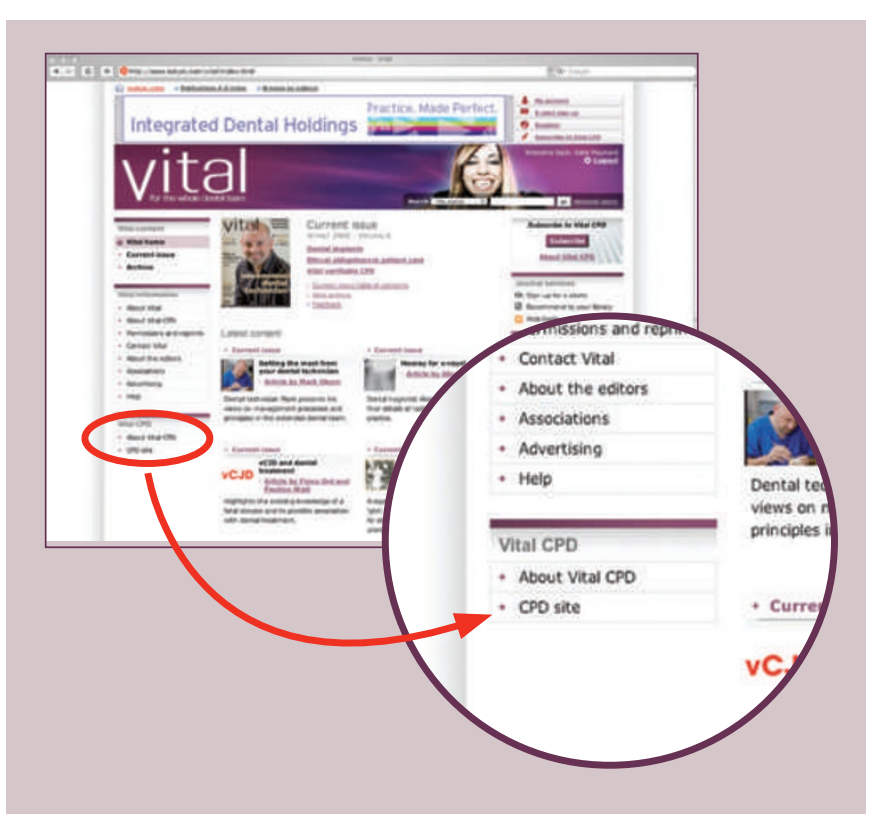

When you are on the Vital CPD website, there is a link at the top through which you can enter your GDC registration number (if you have one - unregistered DCPs are also welcome to take part in Vital CPD). This will ensure that it is included on your CPD certificate when you come to printing it off.

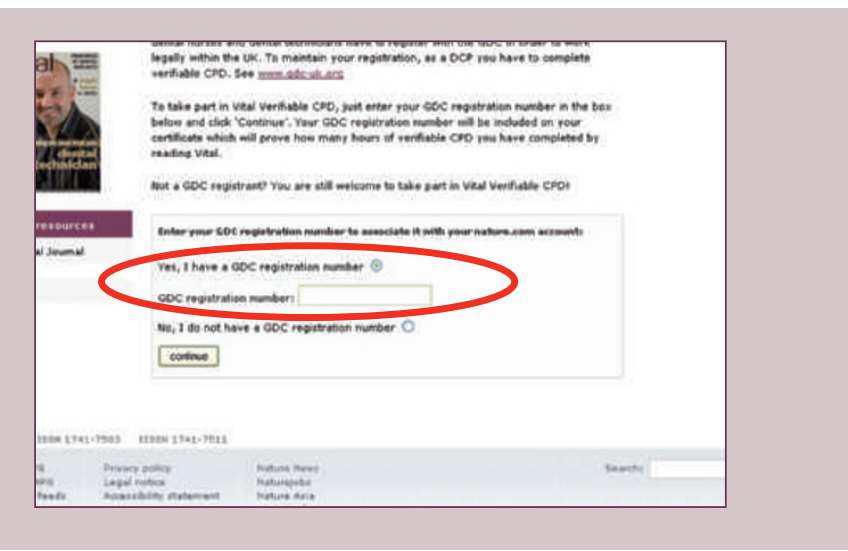

Important note: After your payment has been processed by Vital's publishers, Nature Publishing Group, you will be sent a permanent customer ID number. You will then need to access your account once more and enter your new number into the subscriptions box - as described in point 5. Please keep an eye on your email until you have received your permanent customer ID number, or you may not be able to access the next set of CPD questions.

If you have any problems, email subscriptions@nature.com and you will receive assistance within 24 hours. Send any general queries to vitaleditorial@nature.com. 


\section{Introducing

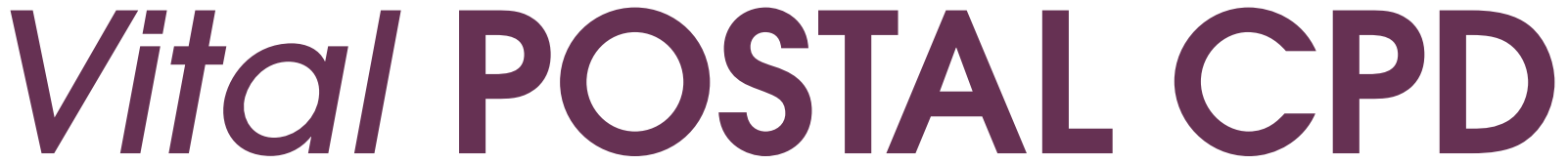

Online Vital verifiable CPD has proved very popular over the last two years and we would like to thank all of our loyal customers for subscribing. However, it has become increasingly apparent that many DCP readers would prefer to return their CPD answers through ordinary post.

We are now delighted to provide Vital verifiable CPD through the post at a cost of $£ 12$ per issue (or $£ 6$ per hour of CPD). The extra cost compared to the online verifiable CPD is to cover the expense of processing your forms and sending your certificates through the post.

To take part in Vital verifiable CPD through the post, please complete this form and return it with your payment to Vital CPD, BDJ Editorial, Nature Publishing Group, 4-6 Crinan Street, London, N1 9XW. One form is required per person. The form can be photocopied.

\section{VITAL POSTAL CPD FORM - AUTUMN 2010}

1. Please PRINT your details below:

First name: Last name: Title:

Address:

Postcode:

Job title:

GDC registration no.

2. Payment details - SUBMISSIONS SENT IN WITHOUT PAYMENT WILL NOT BE PROCESSED.

I enclose a cheque for £12 made payable to Nature Publishing Group $\square$

Or

Please debit the sum of $£ 12$ from the following credit/debit card (tick box):

Visa $\square \quad$ Mastercard $\square \quad$ Switch/Maestro $\square \quad$ Other (please enter) $\square$

Card number:

Expiry date:

Issue no. (Switch/Maestro)

Name of cardholder:

Address of cardholder (if different to above):

3. Tick the answer to each question for each of the CPD articles in this issue.

Article 1

B

C

D

Article 2

Q1 $\square$

$\square$

$\square$

A

B

C

D

Q2

Q3

Q4

$\square$

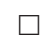

Q1

Q2

Q3

Q4

4. Please add any comments or feedback that you might have below or email vitaleditorial@nature.com. 